\title{
Analysis of Ligeti's Atmosphères by Means of Computational and Symbolic Resources
}

\author{
Ivan Simurra \\ Universidade Federal do Acre \\ ivan.simurra@ufac.br \\ Rodrigo Borges \\ Universidade de São Paulo \\ rcborges@ime.usp.br
}

\begin{abstract}
We report a music analysis study of Atmosphères (1961) from György Ligeti, combining symbolic information retrieved from the musical score and audio descriptors extracted from the audio recording. The piece was elected according to the following criteria: (a) it is a music composition based on sound transformations associated to motions on the global timbre; (b) its conceptual creative intercourse makes direct references to electronic music and sound/timbre techniques from the ancient Renaissance Music; and (c) its sonorities are explored by means of variations on the timbre contrast. From the symbolic analysis perspective, Atmosphères 'timbre content can be discussed considering the entanglement of individual characteristics of musical instruments. The computational method approaches the musical structure from an empirical perspective and is based on clustering techniques. We depart from previous studies, and this time we focus on the novelty curve calculated from the spectral content extracted from the piece recording. Our findings indicate that novelty curve can be associate with five specific clusters, and regarding the symbolic music analysis, three leading music features can be argued: (a) instrumentation changes; (b) distinct pitch chromatic set locations and (c) intensity dynamic fluctuations.
\end{abstract}

Keywords: Music Analysis, Computer Music Analysis, Symbolic Music Analysis, Timbre, Ligeti.

\section{Análise de Atmosphères com recursos simbólicos e computacio- nais}

Resumo: Relatamos estudo de análise musical que utiliza métodos computacionais baseados em descritores de áudio concomitante com análise simbólica de uma peça orquestral. O método foi testado em Atmosphères (1961), de György Ligeti. O objeto foi definido pelos seguintes critérios: (a) trata-se uma composição baseada em alterações sonoras com foco no seu movimento tímbrico global; (b) seu projeto criativo conceitual relaciona técnicas de músicas eletrônicas com música renascentista e (c) suas sonoridades resultantes são exploradas por meio de variação de contrastes tímbricos. Do ponto de vista da análise simbólica proposta neste estudo, as sonoridades de Atmosphères podem ser discutidas por intermédio do entrelaçamento das características individuais dos instrumentos musicais. O método computacional explora a estrutura musical do ponto de vista empírico e é baseado em técnicas de agrupamentos de descritores de áudio por similaridade (homogeneidade). A partir de resultados de estudos anteriores, o atual estudo foca na curva de novidade de conteúdo espectral. Nossos achados indicam que a curva de novidade pode ser associada com cinco agrupamentos distintos. Sob a ótica da análise simbólica, há três principais características musicais: (a) mudanças na instrumentação; (b) regiões distintas de conjuntos de notas musicas dispostas cromaticamente e (c) flutuações dinâmicas de intensidade.

Palavras-chave: Análise Musical, Análise Musical Computacional, Análise Musical Simbólica, Timbre, Ligeti.

O presente artigo desenvolve o trabalho apresentado no V Encontro Internacional de Teoria e Análise Musical, EITAM5 (SIMURRA; BORGES, 2019, p. 305-317). 


\section{Introduction}

Several analysis methods focus on a hack of a music composition into a series of, more-or-less independent sections, materials and data (COOK, 1987, p. 2). The music analysis task taken from the musical sheet in essence furnishes substantial outputs considering the composer's aspects on his or her aesthetic and conceptual planning. However, and it is not uncommon, the analysis performed only by the music sheet may not be enough for the macro- and the micro-structural strand, primarily, over the timbristic universe.

One of the advancement possibilities relating the musical analysis tools are the computational methods which retrieve definitive features in the spectrum domain and magnitude. The computer advances contemporarily witnessed extends the technical means which can be applied either to audio or symbolic data content. An audio record transcription into objective data might result both to visual representation and to statistical interpretation to be likely interact with its music score. At the heart this context, specific features from distinct domains, either by an audio content or the symbolic music material, can be combined simultaneously for a compositional planning subject.

Some of the substantial music designs, notably, since the end of World War 2, were capable to accomplish a crucial perspective for both the timely electronic music resources and the acoustic music instruments. Precisely, it is the instance of Hungarian composer György Ligeti, whose conventional symbolic writing such as in musical pitch, dynamics, rhythmic assemblies are adapted in order to represent new sonic metaphors, primarily, over the electronic sonic corollary (SIMURRA; BORGES, 2019). Infused in the context of Ligeti's creative process his orchestral composition, titled Atmosphères (1961), strictly fits into the antecedent interweaving inference on timbre and textures with little to no concern for traditional compositional rules such as melody, harmony or rhythm (SIMURRA; BORGES, 2019).

The aim of Computational Music Structure Analysis (MÜLLER, 2015) area is to help analysts in finding the acoustic elements composing one musical piece through the information extracted from its recording. This process is usually separated in three consecutive parts: first, meaningful information is extracted from the musical piece audio recording; second, the boundaries of each element are detected in time (local); and then 
they are compared with every other one in the sequence for finding useful relationships among them (global) (KLAPURI et al., 2010). The boundaries detected for these elements can arise from melodic, harmonic or timbre discontinuities, and the relationships between them can be associated to (i) repetition, (ii) novelty or (iii) homogeneity.

Among the three possible relationships between acoustic events, we focus on homogeneity exclusively arising from the timbre dimension. We group similar frequency content in homogeneous groups, and we considering discontinuities in time as their boundaries. It is very important to emphasize that an empirical analysis, like the one presented here, is particular for one specific recording.

Despite of the fact that the subjects underlying the current discussion rely on information provided by the composer, the application of the proposed mixing method to a broader framework should also be viable. These prospects will be the subject of the discussion provided in the following Sections in which we present in a nutshell some of György Ligeti's compositional strategy, Section 2, and the music composition Atmosphères on Section 3. On Section 4 we discuss the major steps of the method settled on the study from the music symbolic inputs and its timbre outputs scrutiny. On the following Section 5 we present the computational analysis proposal. In Section 6 it is adduced the results from method concurrently with their dialogues. Finally, we conclude the study in Section 7 with its closing concern.

\section{György Ligeti}

There are myriad technical and conceptual aspects in which it is possible to depict the compositional strategies of the Hungarian composer György Ligeti (1923-2006). Apart from the Serial Music (specially by the music of Anton Webern) and specific nonmusical aspects of the creative art (by works from Paul Klee) (LEVY, 2017), Ligeti settled most of his music compositions on very complex techniques inspired both in technological input from electronic music studio and ancient music such as Giovanni Pierluigi da Palestrina and Johannes Ockeghem (KIEVMAN, 2003). From the latter, Ligeti settled a comprehensively sound resultant composition motionless which has no culminating peak neither in any music pitch or melodic prevalent profile even though there exist an unrestricted rhythmic contour. 
In the perspective erstwhile argued the resultant sound refers to the melded instrumental layers or voices indeed. It brings on a sort of straightaway auditory stream. It is necessary to listen to the whole piece to realize that even if there are changes even though the totality is static. Indeed, from the Italian Renaissance Music of Palestrina, Ligeti apprehends a pitch-based resultant sound in which its high-level musical outlook restrains any formal structure mix-up with respect to the consonance and dissonance sensitivity (LIGETI, 1958). From either the continuous music flowing or the endless line of music spread evenly over each voice like waves in the see (VÁRNAI et al., 1983, p. 26) in Ockeghem's acknowledgment and the culminating point strikingness for the compositional style of Palestrina, Ligeti was able to focus on the musical structure's permeability (LIGETI, 1958, p. 8) bearing on the sensitiveness degrees of the symbolic elements, such as pitch interval, amplitude of dynamic intensities. From the precedent prospect, Ligeti asseverated that different sound textures may occur synchronously, penetrate each other and even merge into one another completely, whereby the horizontal and vertical density-relationships are altered (LIGETI, 1958, p. 8). Accordingly, such concerns advanced by Ligeti had resonances preponderantly in 1950's Electronic Music techniques.

After a working time period on the Electronic Music Studio of Westdeutscher Rundfunk, in the last years of 1950, György Ligeti acquired new and considerable theoretical and technical substrates to construct his own compositional poetics. His influences on that prospect rely on the perspective of works developed by Herbert Eimert, Karlheinz Stockhausen and Gottfried Koenig. Subsequently, Jennifer Iverson minds that Ligeti disposed of the potential to handle his music experiments by means of an electronic music technique termed as "additive synthesis" depicting the "sound tracks" overlapping alike timbre, harmonic spectrum, noise, roughness and loudness agency (IVERSON, 2010, p. 65-66).

Despite the first electronic music experiments, such as Glissandi and Artikulation, it was from the unfinished electronic project Pièce Électronique $n^{\circ} 3$, predominantly, in which Ligeti ran into electronic music resources liability at that time period. In Pièce Électronique $n^{o} 3$ there were nearly 48 acoustic tracks and it would not be feasible to put them together without the unpredictable and intractable artefact sounds. From this perspective, Ligeti asseverated that nothing but the digital techniques advances would 
overcome such constraints (GRIFFITHS, 1997). Correspondingly, as reported by Levy, Ligeti considered the very content of sonic data on the electronic layer including register, attack qualities and sine-tone versus relation as the straightforward perspectives of musical composition (LEVY, 2009, p. 74).

From the aforementioned outlook, Ligeti strove to inquire into the sonic paradigms relating to the acoustic instrumental impracticability in such perspective. Nevertheless, considering that he was immerse with the electronic systems advancement at that time period in Cologne, he started to treat the music instruments relation by an alternative approach (DE PINA, 2019, p. 2). In order to realize the compositional idea of a "global network", where the individuality of the lines disappears, the composer created an experiment through the overlapping of individual layers of sounds. Ligeti conceived a timbre-based composition in which the individual elements would no longer be audible but en masse, like a "floating timbre" (CATANZARO, 2005, p. 6-8). Ligeti would claim that these experiments would be crucial in the development of his instrumental writing. Following this purpose, each instrument started to be interpreted as a layer, which, superimposed, create an interrelation that causes the various rhythmic events to lose their identities and mask each other, so that the distance between the attacks of the different instruments, added together, are around the threshold of resolution.

In such perspective aligning electronic music tools and the instrumental music composition techniques Ligeti was able to thrive up his works by using chromaticism, polyrhythm and he later dubbed micropolyphony (RICHARD, 1999). It is a particular construct of Ligeti's own understanding of the aesthetic of sound-mass composition (DAVACHI, 2011). Accordingly, it is the own emancipation of the surface texture, the creation of dense sonorities by chord clusters resulting from the suspension of traditional structures of musical time, form, and pitch relation (COPE, 1997). Nevertheless, regardless of the fact that Ligeti did not come up with the electronic studio techniques to be the right medium for his idea, that experience in electronic studios was crucial for his composition and his stylistic development (LEVY, 2006).

Properly, the auditory perception between the successive and the simultaneous sonic events provided an occurrence in which Koenig termed as "sound colour in motion", Bewegungsfarbe, by which discrete sound events are played so fast as to become 
a continuous flowing over the perceptual threshold between individual notes to harmonic effects (IVERSON, 2010; LEVY, 2017; VITALE, 2016). Heeded by Catanzaro, the compositional project researched by Ligeti following Koenig findings, from timbres subjacent a temporal domain in which the individual elements would no longer be audible, alternating sonic cycle ratios by the Bewegungsfarbe or démontage technique. Thus, when the temporal length among note-onset intervals constricted to a less than $50 \mathrm{~ms}$, the auditory perception of the individual ones becomes inaudible (CATANZARO, 2005, p. 7).

A farther creative perspective by which Ligeti indite his sound density fluctuation is through the termed "micropolyphony" technique (LIGETI; MICHEL, 1995). It is a variation of a renaissance canon through which each voice is playing the same set of ordered pitches or nearby, yet to a separate rhythmic pattern with micro interval duration span. The sound saturation provided by the micropolyphony technique makes it impossible to discern individual music elements for the sake of the global sound resultant (SIMURRA; BORGES, 2019, p. 307).

The preceding perspectives ground a creative interlacing in which it ended up smudging the polyphony archetypes, either to the ancient and the Renaissance Music paradigm as heretofore argued, picturing a Ligeti change handling with the resultant sound material for his musical form treatment indeed (LEVY, 2006). It is notably beholden in Ligeti's compositional projects between the late of 1950s and the 1970s primarily in his orchestral work Atmosphères. Therefore, binding the ancient sonic assignment, such as Ockeghem and Palestrina forethoughts, and the electronic resource input, predominantly from the remarks of Stockhausen, Koenig and Eimert, Ligeti translating a "studio experiment" back to the acoustic sphere, used the perceptual blurring technique in his sound-mass orchestral works featuring with Atmosphères (IVERSON, 2017).

\section{Atmosphères}

Inward the Atmosphères perspective, Ligeti focus on timbre and textures in sense of the aforementioned content with little to no concern for traditional compositional rules such as melody, harmony or rhythm. These elements are not the centre of its composition 
however they do play a crucial role in producing dense sounds. The timbre-centred symbolic music analysis from instrumental layers of pitch contours, the symbolic music notes on vertical chromatic design or instrumental techniques such assul tasto, sul ponticello, molto vibrato playing was proposed from Jonathan Bernard (BERNARD, 1987). Notwithstanding, for Bernard, the compositional aim in Atmosphères towards to a "Ligeti's klangfarben piece while its modifications of timbre and dynamics are obviously very significant but the patterns emerging from them are even more important" (BERNARD, 1987, p. 216).

For instance, in Atmosphères, from measure 44 to 53, the micropolyphony technique dilation is utilized, resulting in a mirror-like canon over five octaves gradually pulled inward to a minor third. Although the canon decreases its range, it remains densely chromatic, with no recognizable melodic profile (BAUER, 2001). Moreover, the pitch motion presented on the canon is revealed by timbral dynamic profiles with unique string techniques and color articulations such as sul tasto and sul ponticello, followed by a higher range in music dynamic amplitudes between pppp and ffff. Thus, the canon as a device develops the opening cluster by varying its density, articulation and volume, and implies that the "formless" Atmosphères may actually represent a series of variations on a theme (BAUER, 2001, p. 46).

Considering that in Atmosphères the rhythmic movement is eliminated by overwhelming instrumental onsets emphasizing sustained sounds and avoiding all sense of pulse (SIMURRA; BORGES, 2019), the whole effect of continuity stirs up a sound experience as sound texture whose timbre resultant is peculiarly permeable) (GRIFFITHS, 2010, p. 147). Concurrently there is a harmony construct which is held in suspension by the musical note clusters occurrence as acutely discussed already (Vitale, 2016). Atmosphères ascertained distinct location of the sonic extent between tone and noisy sounds (FLOROS, 2014, p. 65). Referring to Section 2, conceptually inspired by an earlier electronic work named as Pièce électronique $N^{\circ} 3$ (1957-58), Atmosphères in which the focus was in creating sound masses by layering sound waves that were displayed at a myriad of sound frequencies (SIMURRA; BORGES, 2018). The electronic piece is composed based on additive synthesis (IVERSON, 2009, p. 29). For Iverson even though the central compositional issue in the acoustic work Atmosphères is addressed to timbre, the close relationship between Elektronische Musik and Atmosphères provides 
one way of understanding his elevation of timbre in the sound-mass works (IVERSON, 2010, p. 62-63).

Afterwards, Ligeti derelicted the electronic composition in favour to "create a sustained texture" consistently "within which composite sounds would emerge and recede like shadows" (Mayville, 2014, p. 33). The complex instrumental cluster on Atmosphères is equivalent of Pièce électronique's additive synthesis techniques. According to Amy Bauer, Atmosphères represented "polyphony" of tone color, severing timbre from any identifiable harmonic context and creating a laboratory in which "the tone colours were the musical elements preeminent in determining the form" (BAUER, 2001, p. 45).

In Atmosphères for orchestra without percussion (1961) there is no longer any treat with pitch degrees, temporal and metric intertwining, loudness level or timbre endeavour in a serial approach, or indeed any other, featured it as one of the most representative figures on "sound masses" and "tone-color" composition (Simurra; Borges, 2019).

Regardless of Ligeti's reasons for drop the electronic medium off for his particular creative process at that time period of Atmosphères compositional planning, his aim of a "transformation of sound" from the expansion of tone colour, development of montage and canonical structures to create texture and dimension, the juxtaposition of formal dialectics such as stasis and motion or continual and discrete movement, and the perceptible transformation of sound in musical space (DAVACHI, 2011, p. 112). Some of the timbral filtering, glissandi effect, overlapping, superimposition of different textures (initial tone, glissando, filtering, melodic lines), glissandi moving to another static texture (DAVACHI, 2011, p. 127-128). According to Sarah Davachi, it stands for different electronic processes such as transition-filtering in spectral magnitude spot, overlapping and juxtaposition of different rhythms alongside of filtering complex frequencycollections, gradual shaping of dense formations and progressive transition between the amount of set of chromatic pitch and single notes (DAVACHI, 2011, p. 133, 140).

This specific outlook wielding the electronic music-aided acoustic composition stretches out the Ligeti's project on which in his Atmophères' remarks it is about an electronic music, but "set" for orchestra (LEVY, 2006, p. 3). It is a linking panorama amongst acoustic and electronic agencies. 


\section{Symbolic Music Structure}

Symbolic Music Analysis procedure throughout the musical score outputs worthwhile outcome for the conceptual aspects of the structural composition. Under the symbolic analysis circumstances, music timbre issues might be curbed by definite individual interleaving of musical instruments. Coming out of the global structure analysis from Atmosphères a few of figurative music data stand out in its overall creative design: (a) instrumentation changes; (b) distinct pitch chromatic set locations and (c) intensity dynamics fluctuations. It is shown that contrasting timbral changes outcome in diverse dynamic curve profiles both from spectrum and chromogram content. Connecting with findings from (SIMURRA; BORGES, 2019), there are timbral dynamic profiles and colour articulations for changing sound resultant. For such perspective it can be mentioned any contrasting instrument groupings such as the woodwinds, strings and brass perform dissimilar music profiles in range (e.g., low register and high register), dynamic rhythmic behaviours (e.g., static and moving occurrences) and timbre changing variation (e.g., like in air blowing without production of tone, col legno or harmonic glissandi).

\section{Computational Analysis}

The first step of an empirical music analysis process is the extraction of meaningful audio features from the recording of a musical piece. These features (for example frequency spectrum) are usually calculated for short slices of time, starting from the beginning and sliding along the audio signal, and the process originates a sequence of audio features organized in time. In a second step the relationships between these features are analysed, and a temporal musical structure might be revealed. In the following we describe the audio features extraction process, and we describe the applied method in detail.

\section{a. Audio Feature Extraction}

There are several audio features (also known as descriptors) that can be extracted from an audio signal (PEETERS, 2004), depending on the aim of their application. One feature might serve well for visualizing the harmonic content of the recording, another might be more appropriate for the analysis of the timbre. Also, it can happen that some 
of these features are less specific and prioritize the overall characteristics of a musical piece; and on the other hand, it can happen that the analyst is interested in a certain phenomenon and needs to extract more specific audio descriptors.

Audio features are usually extracted from audio signals with the help of a short analysis window, let's say of $50 \mathrm{~ms}$, which slides along the whole signal with juxtaposition. That is to say, the descriptor is calculated for the first $50 \mathrm{~ms}$ in the sound and stored in the memory, the window slides, for example $25 \mathrm{~ms}$, and new values are calculated for the descriptor and stored again in the memory, and so on. The signal comprehended inside a window, also referred to as a frame, is usually multiplied by a smoothing factor for emphasizing the content present in central positions and avoiding discontinuities in the borders.

In this work we have decided for extracting Mel-frequency Cepstral Coefficients (MFCC) as a less specific audio feature, and as more specific ones, we decided for Spectral Centroid and Spectral Flatness. The reason behind the selection as well as the details about the three descriptors are presented in the following.

Mel-frequency Cepstral Coefficients. Human auditory system can be modelled as a set of critical band filters, for example the Mel Scale (PEETERS, 2004), which can be applied to261the frequency spectrum for originating the Mel Spectrogram. The intensity of a sound is not perceived linearly by humans, and for this reason the Mel Spectrogram is represented in its logarithmic form. Finally, the Discrete Fourier Transform (DCT) ${ }^{1}$ is applied to the resulting logarithmic mel spectrogram for obtaining cepstrum coefficients, and the lowest coefficients, typically the first 12 (skipping the first one), are considered as the MFCCs. MFCCs were considered as the standard timbre descriptor for many years and were successfully applied in many tasks like instrument recognition, music genre classification or music recommendation (MÜLLER et al., 2011). They were selected here based on its capacity for providing a small and meaningful representation of the timbre content.

Spectral Flatness. It might be reasonable to assume that in a frequency spectrum calculated for a sound, the energy is as spread over all frequency values as close as the

\footnotetext{
${ }^{1}$ For more information about the DCT the reader may want to check (MÜLLER, 2015).
} 
sound gets to a white noise. On the other hand, the energy is concentrated in a certain frequency value in the case of a tonal sound, or even more concentrated in the case of a sinewave. The Spectral Flatness expresses how the frequency content is spread over frequency values and can be calculated with:

$$
\text { Flatness }=\frac{\sqrt[N]{\prod_{n=0}^{N-1} x(n)}}{\frac{\sum_{n=0}^{N-1} x(n)}{N}}=\frac{\left(\frac{1}{N} \sum_{n=0}^{N-1} \ln x(n)\right)}{\frac{1}{N} \sum_{n=0}^{N-1} x(n)}
$$

Where $x(n)$ is the amplitude of the frequency band $n$. For tonal signals the flatness is close to 0 , and for noisy signals is gets closer to 1 .

Spectral Centroid. It is usually associated to the brightness of a sound, or the "center of mass" of its frequency spectrum. It can be calculated with the formula:

$$
\text { Centroid }=\frac{\sum_{n=0}^{N-1} f(n) x(n)}{\sum_{n=0}^{N-1} x(n)}
$$

Where $x(n)$ is the amplitude of the spectrum in point $n$, and $f(n)$ is the corresponding frequency value.

\section{b. Method}

The method described here was first proposed in (SIMURRA; BORGES, 2018), and is presented in four consecutive parts:

- Feature Extraction - Consecutive MFCC coefficients are extracted from the whole piece and are concatenated all together in one array. MFCCs were extracted with Librosa python library (LIBROSA, [s.n.]), with window size of 2048 and a hop size of 512 samples. The length of the FFT was set to 2048 and the window function to Hanning.

- Clustering - A clustering algorithm is applied on the resulting array for separating the extracted MFCCs in groups (clusters) by similarity. MFFCs ${ }^{2}$ within the same cluster are assumed as homogeneous, and heterogeneous if compared to

2 MFFCs and MFCC coefficients are used interchangeably during the text. 
coefficients from another cluster. The ideal number of clusters is dependent on the data and decided by the clustering algorithm. We applied the Mean Shift clustering algorithm implemented in Scikit Learn Python Library (SCIKITLEARN, [s.n.]). Each cluster has a central coordinate that represents the average coefficients, also referred to as its centroid, identified by an index.

- Codewords - After all centroids are calculated, the method iterates through each MFCC extracted from the musical piece associating it to the closest centroid. The result is another array with the same size as the number of MFCCs, but this time containing consecutive indexes of the closest centroids. A filter is applied for removing extremely fast deviations and maintaining the smoothness of the sequence.

- Novelty - Finally, a novelty curve is calculated for indicating the transitions along the piece that depart from frequent timbre content (clusters observed very often) to novel content (clusters rarely observed), as well as the other way around, from novel to usual content. The level of novelty is calculated as the inverse of the number of MFCCs within a cluster normalized by the total number of MFCCs.

It is worth mentioning that the three first steps correspond to the process of obtaining the bag-of-words representation, first proposed in are of Natural Language Process (NLP), and later adapted to the audio domain (MCFEE et al., 2012).

The clustering process has an interesting property of grouping similar elements together, which emphasizes the global homogeneity of the timbre of the whole piece. The novelty step navigates in these groups highlighting the transitions that occur towards the timbre content that is less frequent, interpreted here as novel. Also, the transition from one cluster to another can be interpreted as the moment when the timbre content changes from one homogeneous neighbourhood to another taking the whole timbre content into account, instead of a local discontinuity.

\section{Results and Discussion}

For the timbral changing motion the very first step was to map the orchestration variations along Atmosphères. The following Figure 1 pictures the music instrumentation groupings by rehearsal marks by cluster of musical pitch locality from musical score. For 
the sake of a viewable representation, letter $P$ and the last square of the rehearsal marks consists of "noisy sound" outputs and consequently it was settled to involve the whole ambit of the musical pitch register wilfully.

From the symbolic music analysis over the instrumentation/orchestration disposition, the chromatic set scope is autonomous either by the density of music instruments or their overlap mixing. It is worth to mention the independent design between the music instrument set up on narrower set of musical notes in letters $\mathrm{K}$ and $\mathrm{L}$ for instance and their opposed one on letters $\mathrm{F}, \mathrm{H}$ and $\mathrm{O}$ indeed.

Figure 1 - Diagram analysis of the music instrumentation groupings in Atmosphères. Y-axis stands for musical pitch region from the lowest note to the highest one. X-axis represents the rehearsal marks along the entire score (Ligeti, 1980). Color degrees correspond to each of rehearsal steps. Fl for flute, Pc for Piccolo, $\mathrm{Ob}$ for Oboe, $\mathrm{Cl}$ for Clarinets, Bsn for Bassoon, Hn for Horn, Tp for trumpet, Tbn for Trombone, Ta for Tuba, Pno for Piano, Vlns for Violins, Va for Viola, Vc for Violoncello and DB for Double Bass.

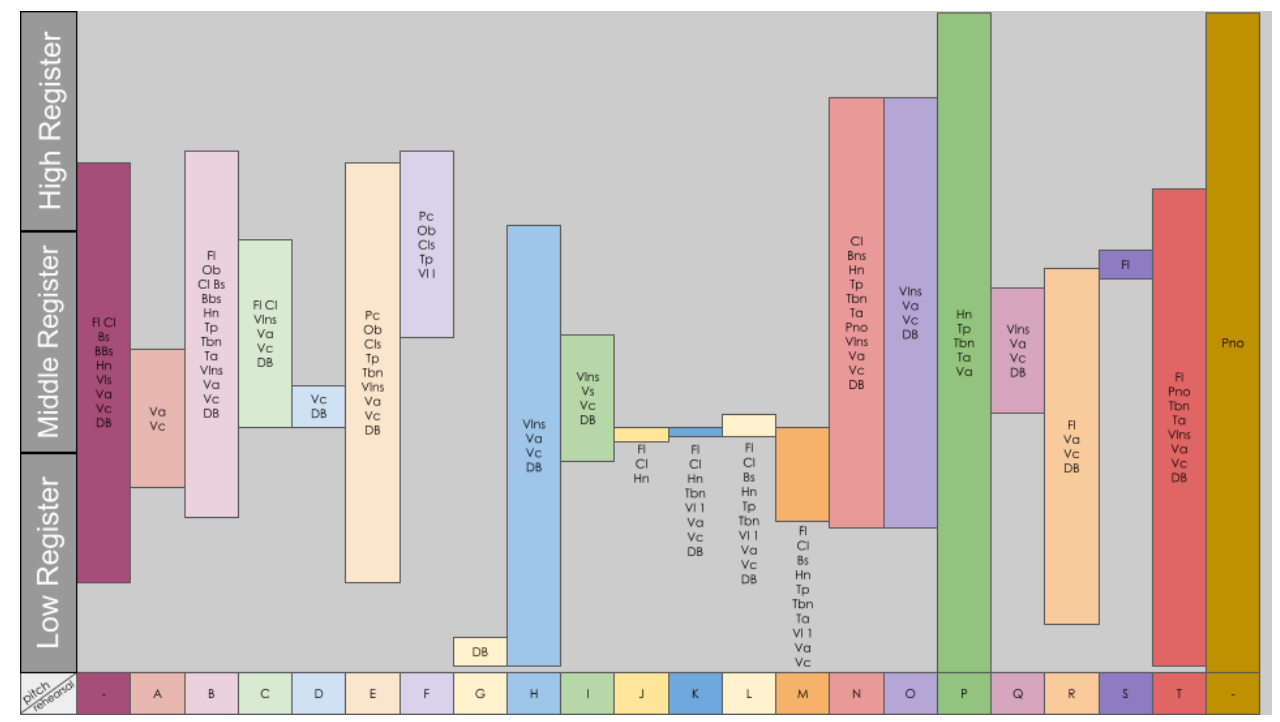

Source: Elaborated by the authors.

The computational method was applied to the recording of Atmosphères performed by the Berlin Philharmonic Orchestra, conducted by maestro Jonathan Nott on The Ligeti Project II (LIGETI, 2020) and the results are presented in Figure 2 and 3. 
Figure 2 - Left: The first two Mel-frequency Cepstral Coefficients extracted from the Atmosphères recording. Right: A graph representation of transitions between clusters.
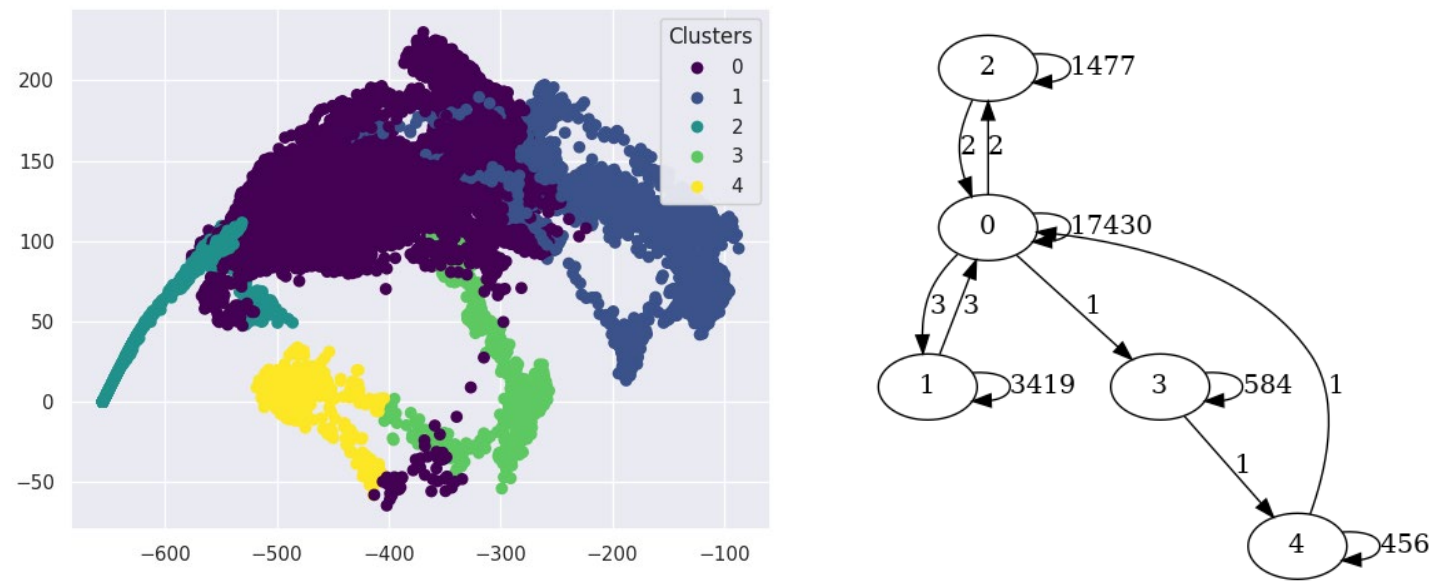

Source: Elaborated by the authors.

Among the 12 Mel-frequency Cepstral Coefficients extracted for the whole recording, the first two are presented on the left side of Figure 2 for the sake of visualization. The first coefficient is represented in $\mathrm{x}$ axis, and the second one in the $\mathrm{y}$ axis. The number of clusters was defined by the Mean Shift clustering algorithm and the indexes depend on the number MFCCs attributed to each cluster, that is, cluster 0 is most frequent one and cluster 4 is the one associated to fewer cepstrum coefficients. It is worth noticing that each point in this graph is a MFCC extracted from the piece and that MFCCs within each cluster are more similar to each other than if compared to MFCCs from another clusters.

The graph in the right side of the same figure brings information about the temporal evolution of the piece, or more specifically, it presents an overview on the transitions between clusters. One can imagine the audio recording evolving in time, changing from one cluster to another or staying in the same cluster where it was before. The graph describes how many and how these transitions happened during the whole piece. It provides no information on where the piece started but gives already a notion of a potential temporal structure. 
Figure 3 - Top: the spectrum extracted from the piece recording; Middle: the clusters corresponding to each frame of the piece; Bottom: the novelty curve proportionally converses to the cluster population. Red and white dashed lines indicate relevant transitions to and from regions containing novel timbral content, respectively.

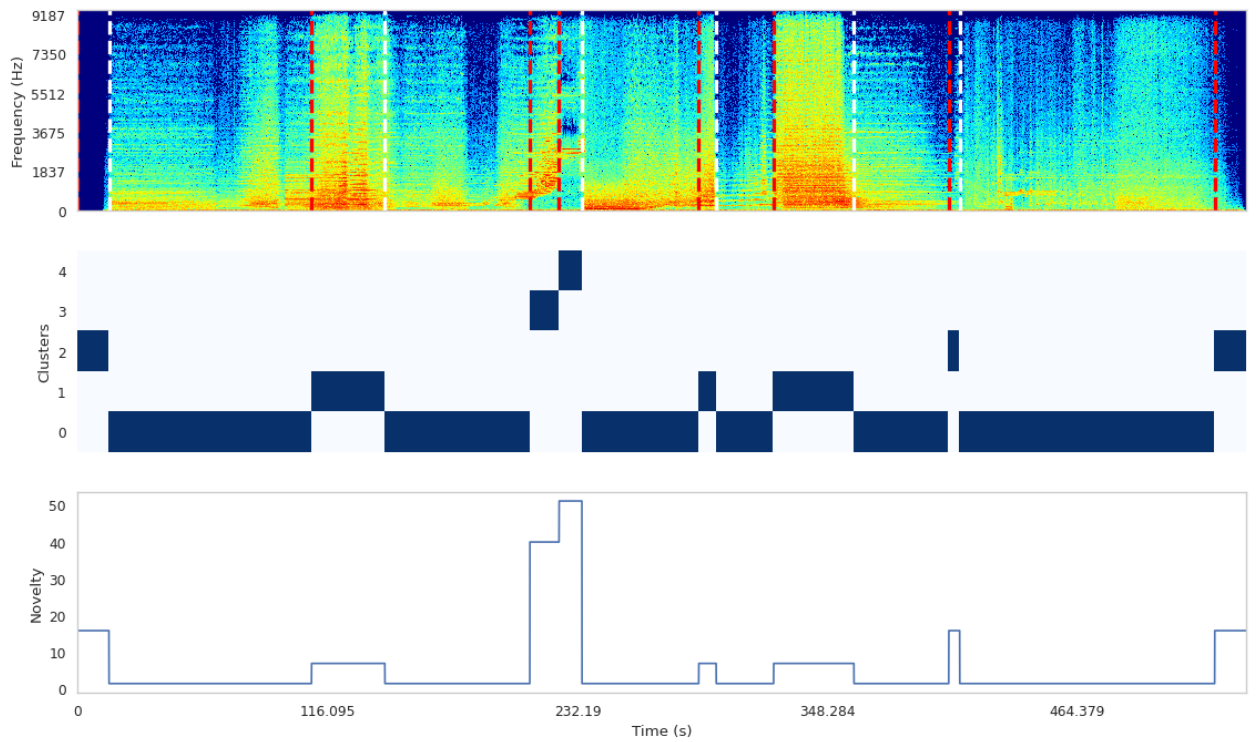

Source: Elaborated by the authors.

The novelty curve described in Section 5.b is presented in Figure 3, together with the spectrogram of the audio recording, and the transitions between MFCCs clusters. The moments in which these transitions occur are indicated as dashed lines in the spectrogram, and the number of MFCCs associated to each cluster is remembered once more: red lines are used for transitions to less frequent clusters (associated to few coefficients), and white lines are user for transitions to more frequent clusters (associated to many coefficients).

When comparing the first and second rows of this figure, the spectrogram and the transitions between clusters, one can intuitively make some associations, for example, it might be reasonable to assume that cluster number 2 comprehends silent or low dynamic audio features extracted from the piece. Cluster 1 is associated to higher dynamics and with a wider frequency spectrum. Cluster 0 is the most frequent one (observed all along the piece), from which most of transitions depart from.

Novel timbre content is assumed here as the one associated with less frequent clusters in the context of the analysis. The novelty curve is presented in the third row of Figure 3, combining information about the cluster's population and the moment when transitions happen, for indicating the level of novelty associated to each transition. In 
other words, in the case when there is a timbre material that is only used for a short period during the whole piece, it might be reasonable to believe that when it is presented to the listener it will be listened as novel stimulus. In our analysis we see two clusters with considerably higher degree of novelty, 3 and 4, and we can also see the increase in the novelty curve when there are transitions to these clusters.

Preponderantly on the current analysis approach of Atmosphères, each of the distinct cluster is linked by cluster 0 anyhow. The single deviation is centred between 175 " and 231" in which cluster 0 rounds cluster 3 and cluster 4 in sequence (Figure 3Middle describing the clusters corresponding to each frame of the piece). For the orchestration settings, there are categorical instrumentation groupings and blending idiosyncratic music instrument families, such as strings and woodwinds in cluster 0 instances. It is in line with the aforementioned instrumentation changes in (a) and the distinct pitch chromatic set locations in (b) suggested on Section IV. Figure 4 depicts the discrete orchestration settings by clusters from Figure 3.

Figure 4 - Cluster analysis from music instrumentation settings on Atmosphères. Y-axis stands for musical pitch region from the lowest note to the highest one.

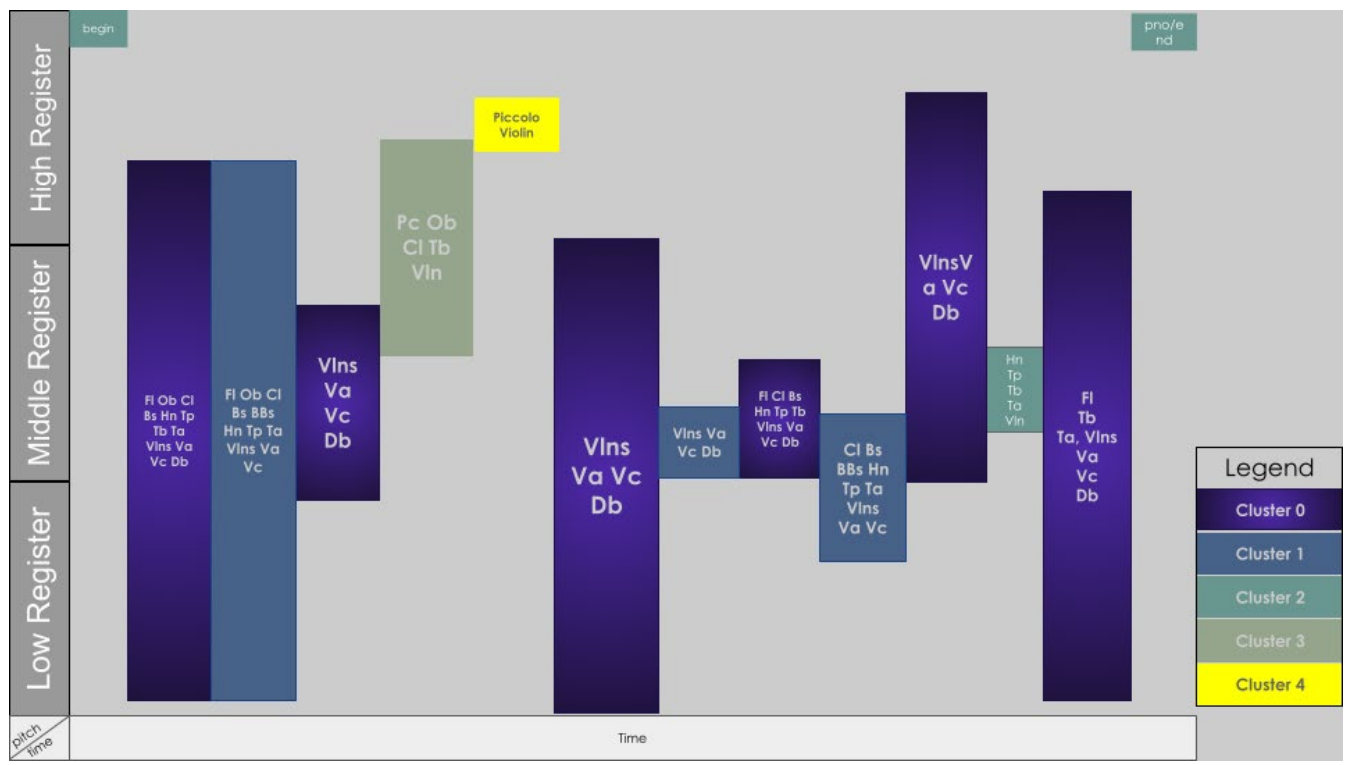

Source: Elaborated by the authors. 
Along with instrumentation and orchestration contrasts further timbral dynamic profiles and colour articulations for changing sound resultant are concurrent on the light of (a) in Section 4. The Figure 5 pictures the exceptional cluster 2 which is situated intrinsically in Atmosphères because the two instances of cluster 2 correspond to the beginning and the end of the piece relating to "music silence" or "noisy sound". The cluster 2 in Atmosphères is associated with some noisy sound outputs such as air blowing and toneless bowing techniques in woodwind and string instruments.

Figure 5 -Atmosphères excerpt associated with noisy sound outputs by specific instrumentation techniques in woodwind and string instruments.

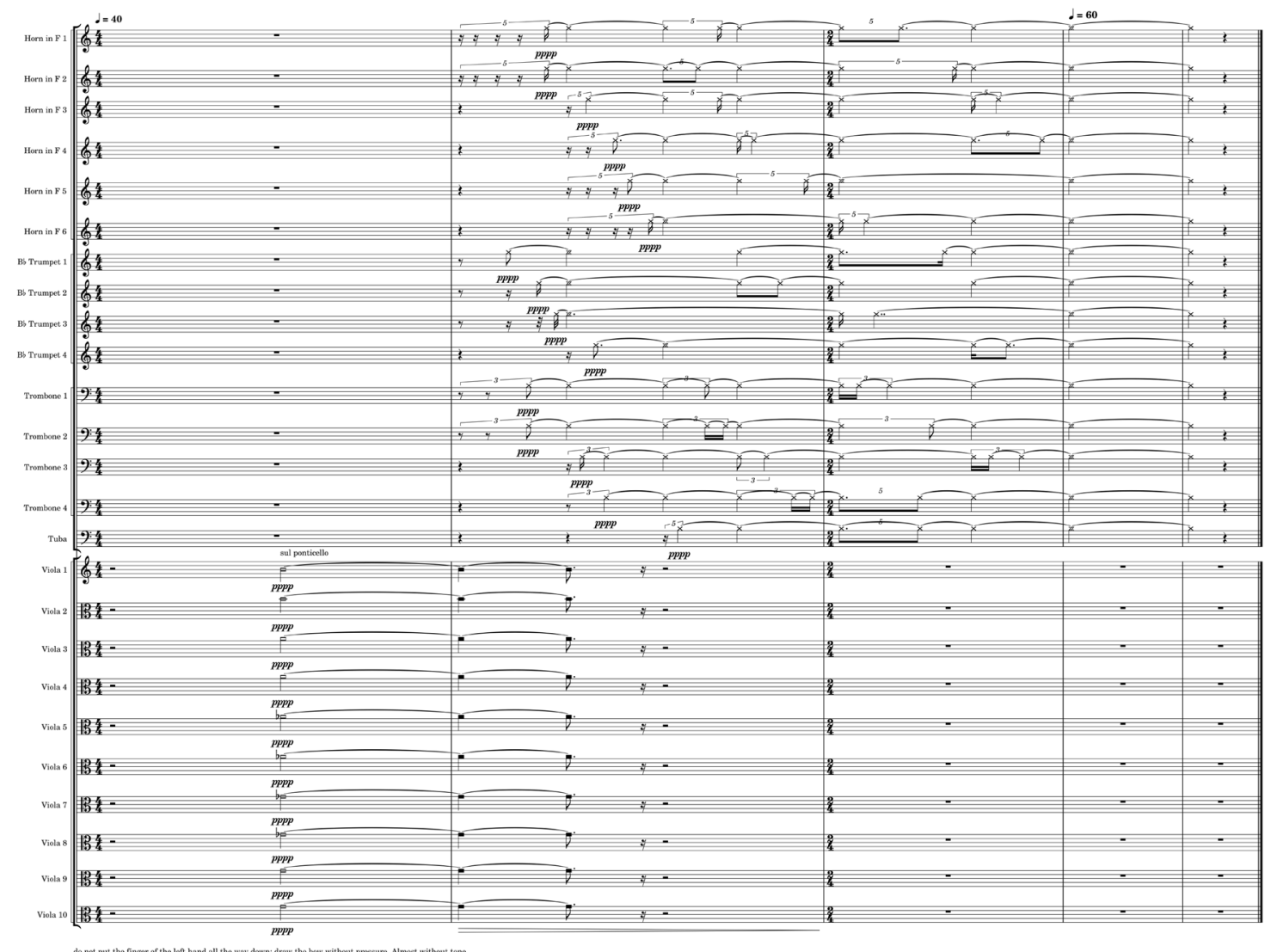

Source: Elaborated by the authors.

For the third musical features argued in Section 4, namely (c) intensity dynamics fluctuations, the foremost occurrence of cluster 2 in Atmosphères stands for the manifold of intensity envelopes from the same instrumentation settings against the previous cluster 
0. The following Figure 6 illustrates the intensity profiles for the excerpt in which the filled black "<" sign corresponds to crescendo and the flip-side ">" sign relates to decrescendo intensity amplitude fluctuation.

Figure 6 - The intensity dynamic analysis in Atmosphères linked by one of the cluster 1 instance from Figure 3. Y-axis corresponds to music instruments, $\mathrm{Fl}$ for Flutes, $\mathrm{Ob}$ for Oboes, $\mathrm{Cl}$ for Clarinets, Bs for Bassoons, Hn for Horns, Tp for Trumpets, VlnI for Violin I, VlnII for Violin II, Va for Viola, Vc for Violoncello and $\mathrm{Cb}$ for Double Bass. $\mathrm{X}$-axis relates to measures as reported in the musical score.

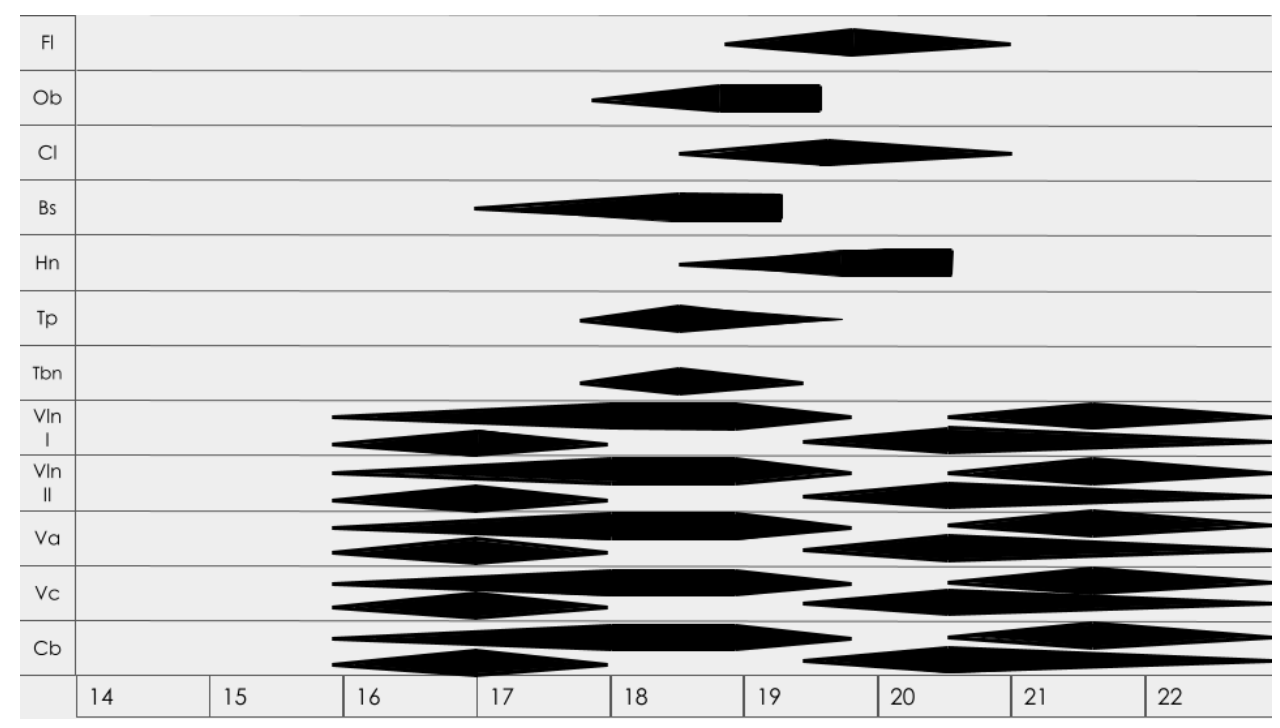

Source: Elaborated by the authors.

Exclusively for the cluster 3 and cluster 4 in sequence and the successive cluster 0 disposal which corresponds to the novelty curve acme from Figure 3, contrasting musical note settings concurrent with instrumentation groupings tied in the compelled pitch chromatic set locations. The subsequent Figure 7 represents the music symbolic transition between the cluster 4 which it is related with piccolo and violin at the highest register pitch chromatic and the cluster 0 subjected to the Double Bass groupings at the lowest register pitch chromatic bunch. 
Figure 7 - The music symbolic contour between cluster 4 and cluster 0 shift from the musical score.

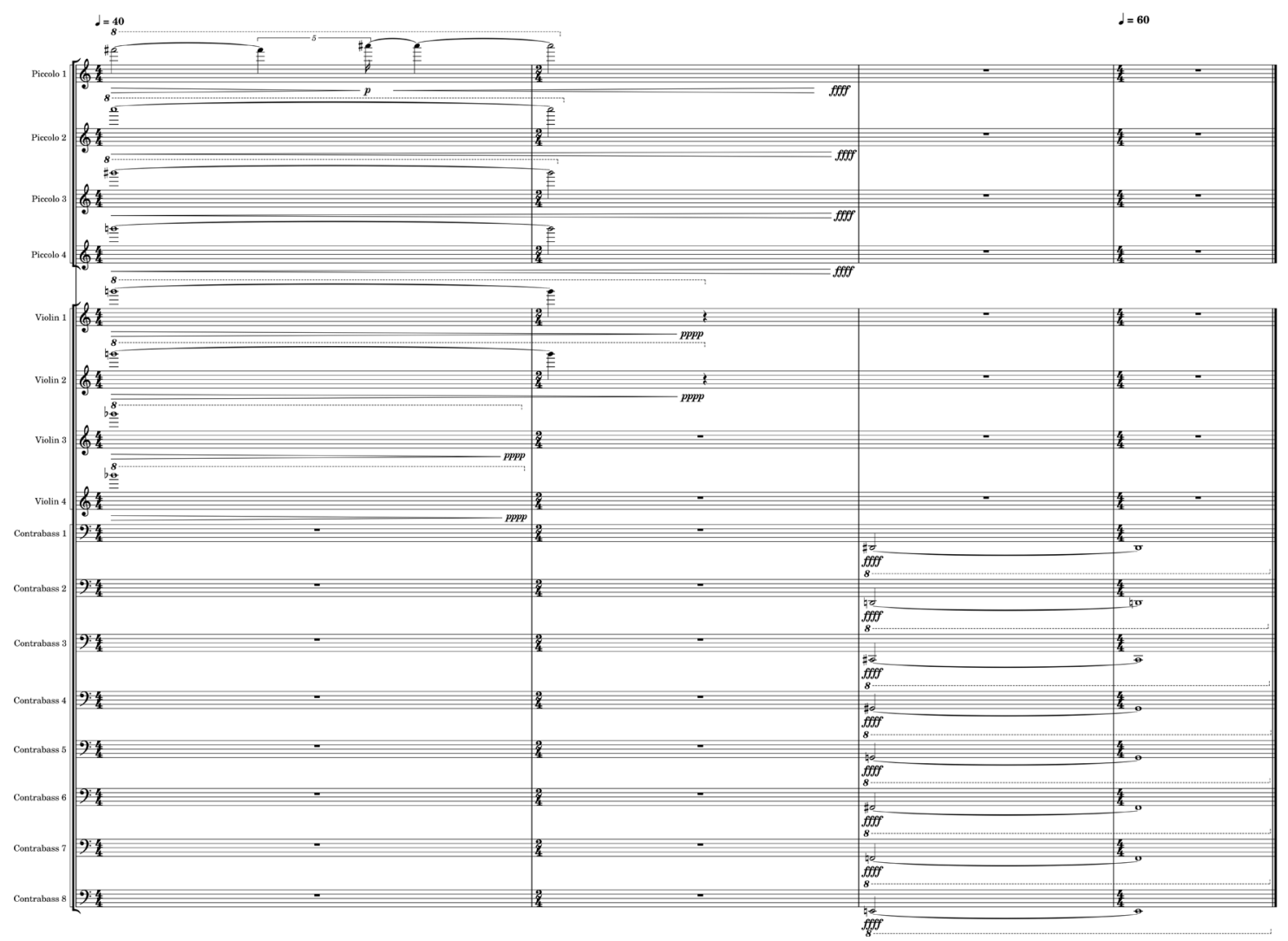

Source: Elaborated by the authors.

Apropos for the novelty cluster bend as previously mentioned some thorough features are feasible pointed out. Apart from both the contrasting musical pitch register and the music instrumentation/orchestration contrasts, "noisy sound" outputs remain nearly flexible. From the symbolic music analysis, the following Figure 8 features an allegorical chromatic set fluctuation corresponding to cluster 0 , the clusters 3 and 4 sequence before the standard supersaturated canon previously reported on Section III. The excerpt evinces the contextual creative planning in Section 2 relating to electronic music techniques such as filtering and the Bewegungsfarbe. In agreement with the already declared for the supersaturated canon (SIMURRA; BORGES, 2019), the block-like structural planning highlights the chromatic set shifting in string instruments.

Meanwhile, pursuant to the Spectral Flatness and the Spectral Centroid the considered excerpt asseverates the distinct audio features interlacing profiles. The Figure 9 depicts each of the mentioned audio features along with the spectrogram. 
Figure 8 - Music Instrument layers corresponding to the sequence of cluster 0, cluster 3, cluster 4 and the supersaturated canon (Simurra; Borges, 2019), cluster 0 and cluster 1 in Atmosphères. Y-axis stands for musical pitch region from the lowest note to the highest one. $\mathrm{X}$-axis represents time in seconds according to the musical score data (Ligeti, 1980).

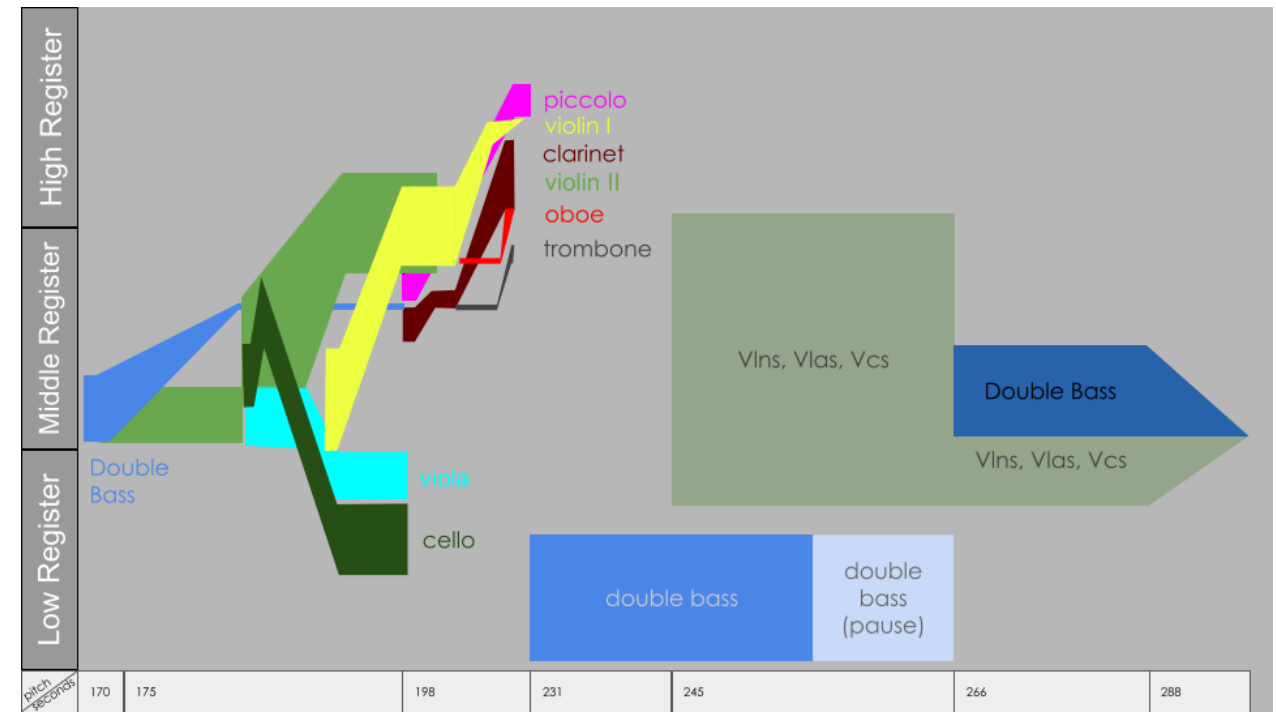

Source: Elaborated by the authors.

Figure 9 - Top: the spectrum extracted from the excerpt containing the novelty curve apex from Figure 3; Middle: the Spectral Flatness; Bottom: the Spectral Centroid.

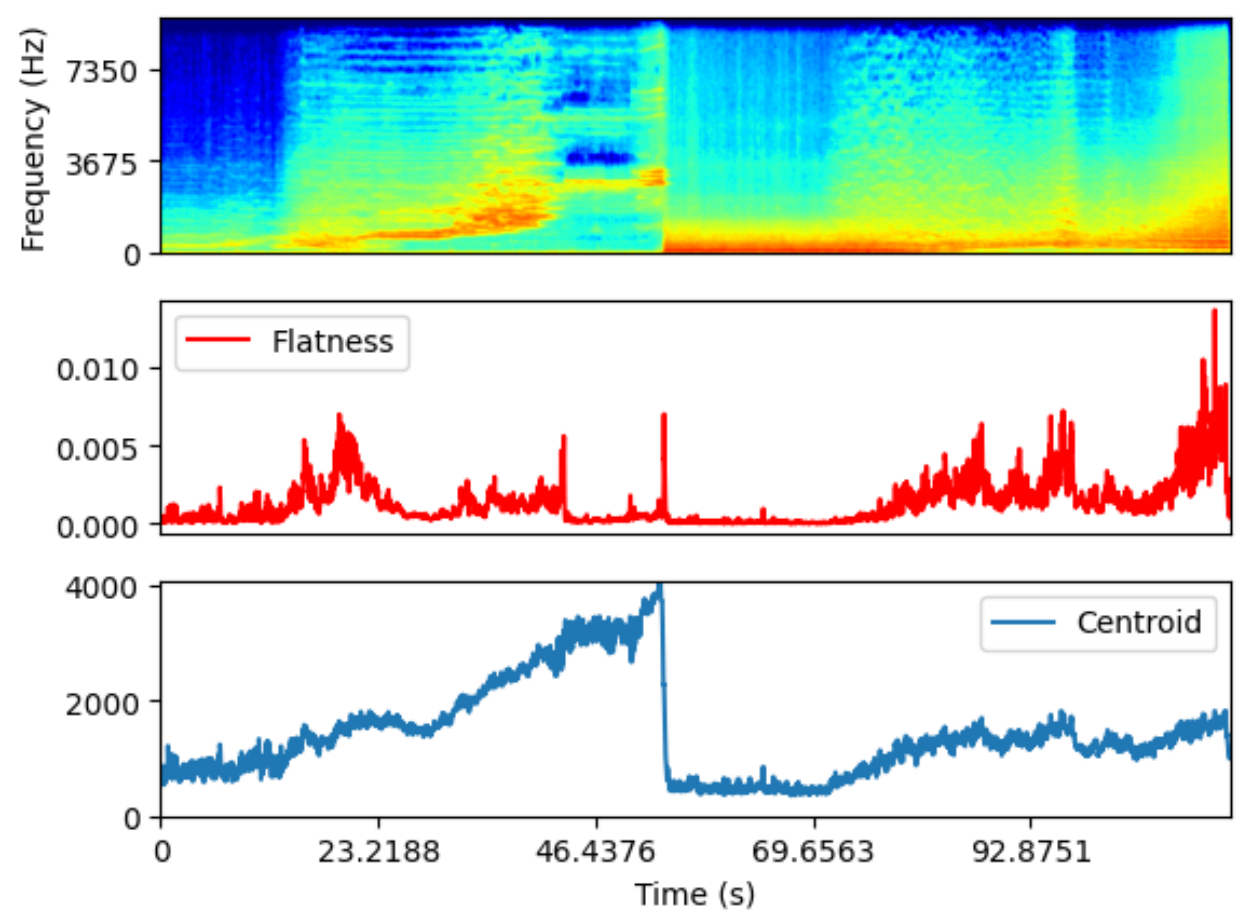

Source: Elaborated by the authors. 
Let's recall that the spectral flatness expresses how a frequency spectrum is distributed417along an available range and lets also recall that the spectral centroid of a sound expresses its brightness, or more specifically, the frequency value in which its frequency spectrum is concentrated. Briefly said, the former indicates if a spectral distribution approximates a tone, and the later indicates the resulting tone, in the case it exists.

The excerpt observed in Figure 9 corresponds to the one within which the greatest variations in the novelty were observed according to Figure 3. In the first half of the excerpt a constant increase in the centroid values suggests that the orchestra is sounding linearly higher in the pitch scale, almost like an artificially generated sound, whilst the flatness values remain relatively stable and low. In the second half there is an unambiguous shift in pitch scale region towards to the low chromatic set accomplished by the Double Bass ensemble. Moreover, the spectral centroid profile confederates it onto a darker sound (Figure 7). From the nearly 70 seconds in the Figure 9, there is a sparse motion conflux for both spectral centroid and flatness forward to higher indexes individually.

Accordingly, this ending part of the second half is held by the supersaturated canon part suggesting that, in agreement with any of the leading music features in Section IV such as (b) and (c), although the pitch material over the portion remains invariant and regular settled on chromatic content such as set of pitches, its dynamic organization from both rhythmic and metric structures aims to compose dense sound instances through spectral outcome and microvariation of chromatic handling (SIMURRA; BORGES, 2019).

\section{Conclusions}

The entire path of the presented music study settled an engaging analysis method combining distinct features from autonomous domains, from the audio recording and the music symbolic score, in a multimodal perspective. Atmosphères is developed by mixing the conceptual designs both from ancient music and the electronic music studio assets either by technical or compositional means. From the old-fashioned music aesthetics, chiefly by Renaissance Music, Ligeti focused on the individuality of the music features 
based on their intercommunicability, pertinency and permeability magnitude. For the electronic music advance inputs, in Atmosphères the filtering processes of textural layers, represented by each musical instrumental of the orchestral settings, where each layer performs a distinct process while they focus on the very same sound objective: global timbre transformation. However, there are different transitions among these layers: sometimes the filtering is done abruptly, in others one they are subtly led from the entire spectral region, across the pitch chromatic set.

A further perspective in this Atmosphères study was associated with the instrumentation changes which permit a timbre colour variation from the inner sound qualities either from their idiosyncrasies or in mixings ensembles. Moreover, intensity dynamic variations indicate that the energy aptitude also leads onto timbre differences in spectral magnitude regions. From this perspective intertwining acoustic instrumental music involved by techniques or process settled by electronic music, this arrangement might be potentially correlated with the technomorphism view (HOLMES, 2019; HOLMES, 2014; CATANZARO, 2005). Nonetheless, further studies would be necessary to test this hypothesis. Regardless of the forthcoming inquiries the current study yielded a consistent music analysis aided in dealing with the very composition planning in which symbolic music content and audio data resources are treated equivalently.

\section{References}

BAUER, Amy. Composing the sound itself: secondary parameters and structure in the music of Ligeti. Indiana Theory Review, v. 22, n. 1, p. 37-64, 2001.

BERNARD, Jonathan W. Inaudible structures, audible music: Ligeti's problem, and his solution. Music Analysis, v. 6, n. 3, p. 207-236, 1987.

CATANZARO, Tatiana. Do descontentamento com a técnica serial à concepção da micropolifonia e da música de textura. In: CONGRESSO DA ASSOCIAÇÃO NACIONAL DE PESQUISA E PÓS-GRADAÇÃO EM MÚSICA, 15., 2005, Rio de Janeiro. Anais... Brasil: ANPPOM, 2005. p. 1246-1255.

COOK, Nicholas. A guide to musical analysis. New York: Oxford University Press, 1994. 
COPE, David. Techniques of the contemporary composer. Wadsworth: Schirmer Books, 1997.

DAVACHI, Sarah. Aesthetic appropriation of electronic sound transformations in Ligeti's Atmosphères. Musicological Explorations, v. 12, p. 109-110, 2011.

DE PINA, Cláudio Miguel Andrade Fonseca. Ligeti's harmonies, ENCONTRO INTERNACIONAL DE INVESTIGAÇÃO DE ESTUDANTES EM MÚSICA E MUSICOLOGIA, 1., 2019, Évora. Anais... Évora: CESEM, Universidade de Évora, 2019.

FLOROS, Constatin. György Ligeti: Beyond Avant-garde and Postmodernism. Frankfurt: Peter Lang $\mathrm{GmbH}, 2014$.

GRIFFITHS, Paul. György Ligeti: The Contemporary Composer. London: Robinson Books, 1997.

GRIFFITHS, Paul. Modern music and after. 3. ed. New York: Oxford University Press, 2010.

HOLMES, Bryan. Tecnomorfismo em música: uma visão teórica e prática. Tese (Doutorado) Programa de Pós-Graduação em Música, Universidade Federal do Rio de Janeiro, 2019.

HOLMES, Bryan. Tecnomorfismo em música: surgimento do conceito e revisão bibliográfica. In: CONGRESSO DA ASSOCIAÇÃO NACIONAL DE PESQUISA E PÓS-GRADAÇÃO EM MÚSICA, 24., 2014, São Paulo. Anais... Brasil: ANPPOM, 2014.

IVERSON, Jennifer. Shared compositional techniques between György Ligeti's Pièce Électronique no. 3 and Atmosphères. Mitteilungen der Paul Sacher Stiftung, v. 22, p. 29-33, 2009.

IVERSON, Jennifer. The emergence of timbre: Ligeti's synthesis of electronic and acoustic music in Atmosphères. Twentieth Century Music, v. 7, n. 1, p. 61-89, 2010.

IVERSON, Jennifer. Learning the studio: Sketches for mid-century electronic music. Contemporary Music Review, v. 36, n. 5, p. 362-387, 2017.

KIEVMAN, Carson. Ockeghem and Ligeti: The Music of Transcendence. Thesis (Ph.D.) Princeton University, 2003.

KLAPURI, Anssi; PAULUS, Jouni ; MÜLLER, Meinard. Audio-based music structure analysis. In: INTERNATIONAL SOCIETY FOR MUSIC INFORMATION RETRIEVAL, 11., 2010, Utrecht, Netherlands. Proceedings... Utrecht, Netherlands: ISMIR, 2010.

LEVY, Benjamin Robert. The electronic works of György Ligeti and their influence on his later style. Thesis (Ph.D.) - University of Maryland, 2006.

LEVY, Benjamin Robert. Shades of the studio: Electronic influences on Ligeti's Apparitions. Perspectives of New Music, v. 47, n. 2, p. 59-87, 2009. 
LEVY, Benjamin Robert. Metamorphosis in Music: The Compositions of György Ligeti in the 1950s and 60s. New York: Oxford University Press, 2017.

LIBROSA. A python package for music and audio analysis. [s.n.]. Available at: https://librosa.org/doc/latest/index.html. Accessed: 24 April 2019.

LIGETI, György. The Ligeti Project II: Lontano, Atmosphères, Apparitions, San Francisco Polyphony, Concert Românesc. The Berlin Philharmonic Orchestra, conducted by Jonathan Nott. London: Warner Classics International, 2020. 1 compact disc.

LIGETI, György. Metamorphoses of musical form. Die Reihe, v. 7, p. 5-19, 1958.

LIGETI, György. Atmosphères. 6. ed. Donaueschingen: Universal Edition, 1980.

LIGETI, György; MICHEL, Pierre. Entretiens avec György Ligeti. Paris: Minerve, 1995.

MAYVILLE, Stephanie. The compositional techniques and influences behind Ligeti's' Atmosphères. Intermezzo, v. 1, p. 30-38, 2014.

MCFEE, Brian; BARRINGTON, Luke; LANCKRIET, Gert. Learning content similarity for music recommendation. IEEE Transactions on Audio, Speech, and Language Processing, v. 20, n. 8, p. 2207-2218, 2012.

MÜLLER, Meinard; ELLIS, Daniel; KLAPURI, Anssi; RICHARD, Gaël. Signal processing for music analysis. IEEE Transactions on Audio, Speech, and Language Processing, v. 5, n. 6, p. 1088-1110, 2011.

MÜLLER, Meinard. Fundamentals of Music Processing: Audio, Analysis, Algorithms, Applications. 1. ed. Switzerland: Springer Publishing Company, 2015.

PEETERS, Geoffroy. A large set of audio features for sound description (similarity and classification) in the CUIDADO project, Technical Report. Paris: IRCAM, 2004.

TOOP, Richard. György Ligeti. London: Phaidon Press, 1999.

SCHAUB, Stéphan; SIMURRA, Ivan; TAVARES, Tiago Fernandes. Mixing symbolic and audio data in computer assisted music analysis a case study from Harvey's Speakings (2008) for orchestra and live electronics. In: SOUND AND MUSIC COMPUTING CONFERENCE, 10., 2013, Stockholm, Sweden. Proceedings... Stockholm: SMAC, 2013.

SCIKIT-LEARN. Machine Learning in Python. [s.n.]. Available at: https://scikitlearn.org/stable/index.html. Accessed: 24 April 2019.

SIMURRA, Ivan Eiji; BORGES, Rodrigo. (2018). Combining automatic segmentation and symbolic analysis based on timbre features-a case study from Ligeti's Atmosphères. In: 
INTERNATIONAL CONFERENCE OF STUDENTS OF SYSTEMATIC MUSICOLOGY, 11. 2018, Belo Horizonte. Proceedings... UFMG: SysMus, 2013. p. 76-78.

SIMURRA, Ivan Eiji; BORGES, Rodrigo. Analysis of Ligeti's Supersaturated Canon in Atmosphères by Means of Computational and Symbolic Resources. In: ENCONTRO INTERNACIONAL DE TEORIA E ANÁLISE MUSICAL, 5., 2019, Campinas. Anais... Campinas, Universidade Estadual de Campinas, 2019. p. 305-317. Disponível em: https://eitam5.nics.unicamp.br/wp-content/uploads/2020/12/EITAM5-

paper_22_SimurraI_BorgesR-pp_305-317.pdf. Acesso em: 27 maio 2021.

VÁRNAI, Péter; HÄUSLER, Jose; SAMUEL, Claude. György Ligeti in conversation with Péter Várnai, Josef Häusler, Claude Samuel, and himself. Trans. Gabor J. Schabert, Sarah E. Soulsby, Terence Kilmartin and Geofrey Skelton. London: Eulenburg, 1983.

VITALE, Claudio. A gradação nas peças 5 e 6 das dez peças para quinteto de sopros de György Ligeti. In: ENCONTRO INTERNACIONAL DE TEORIA E ANÁLISE MUSICAL, 1., 2009, São Paulo. Anais... São Paulo, Universidade Estadual Paulista, 2009.

VITALE, Claudio. Bewegungsfarbe e cânone sobressaturado: Atmosphères de György Ligeti. Vórtex, Curitiba, v. 4, n. 2, p. 1-17, 2016. 
Revista Música, v. 21 n. 1 - Dossiê Música em Quarentena (parte II); Dossiê Encontro Internacional de Teoria e Análise Musical - 10 Anos Universidade de São Paulo, julho de 2021

ISSN 2238-7625 